\title{
THE
}

\section{Gaseous and Freely-Dissolved PCBs in the Lower Great Lakes based on Passive Sampling: Spatial Trends and Air-water Exchange}

Ying Liu

Siyao Wang

Carrie A. McDonough

Mohammed Khairy

Derek Muir

Follow this and additional works at: https://digitalcommons.uri.edu/gsofacpubs

The University of Rhode Island Faculty have made this article openly available.

Please let us know how Open Access to this research benefits you.

This is a pre-publication author manuscript of the final, published article.

Terms of Use

This article is made available under the terms and conditions applicable towards Open Access

Policy Articles, as set forth in our Terms of Use.

\section{Citation/Publisher Attribution}

Liu, Y., Wang, S., McDonough, C. A., Khairy, M., Muir, D., Helm, P., \& Lohmann, R. (2015). Gaseous and Freely-Dissolved PCBs in the Lower Great Lakes based on Passive Sampling: Spatial Trends and Air-water Exchange. Environmental Science \& Technology, Advanced online publication.

Available at: http://www.dx.doi.org/10.1021/acs.est.5b04586

This Article is brought to you for free and open access by the Graduate School of Oceanography at DigitalCommons@URI. It has been accepted for inclusion in Graduate School of Oceanography Faculty Publications by an authorized administrator of DigitalCommons@URI. For more information, please contact digitalcommons-group@uri.edu. 


\section{Authors}

Ying Liu, Siyao Wang, Carrie A. McDonough, Mohammed Khairy, Derek Muir, Paul Helm, and Rainer Lohmann

This article is available at DigitalCommons@URI: https://digitalcommons.uri.edu/gsofacpubs/147 
1 Gaseous and Freely-Dissolved PCBs in the Lower Great Lakes

2 based on Passive Sampling: Spatial Trends and Air-water

3 Exchange.

4

5 YING LIU ${ }^{\dagger, \ldots,}$, SIYAO WANG ${ }^{\dagger}$, CARRIE A. MCDONOUGH ${ }^{\ddagger}$, MOHAMMED KHAIRY $^{\ddagger}, \phi$,

6 DEREK MUIR ${ }^{\S}$, PAUL HELM ${ }^{\#}$, RAINER LOHMANN ${ }^{\ddagger}{ }^{*}$

7

8

${ }^{\dagger}$ State Key Laboratory of Pollution Control and Resources Reuse, Shanghai Key Lab

* To whom correspondence should be addressed

E-mail address: rlohmann@mail.uri.edu (R. Lohmann), Phone: 401-874-6612;

Fax: 401-874-6811, liu_ying@tongji.edu.cn (Y. Liu). 


\section{ABSTRACT}

Polyethylene passive sampling was applied to quantify gaseous and freely-dissolved polychlorinated biphenyls (PCBs) in the air and water of Lakes Erie and Ontario during 2011-2012. In view of differing physical characteristics and the impacts of historical contamination by PCBs within these lakes, spatial variation of PCB concentrations and air-water exchange across these lakes may be expected. Both lakes displayed statistically similar aqueous and atmospheric PCB concentrations. Total aqueous concentrations of 29 PCBs ranged from $1.5 \mathrm{pg}$ $\mathrm{L}^{-1}$ in the open lake of Lake Erie (site E02) in 2011 spring to $105 \mathrm{pg} \mathrm{L}^{-1}$ in Niagara (site 0n05) in 2012 summer, while total atmospheric concentrations were 7.7-634 $\mathrm{pg} \mathrm{m}^{-3}$ across both lakes. A west-to-east gradient was observed for aqueous PCBs in Lake Erie. River discharge and localized influences (e.g., sediment resuspension and regional alongshore transport) likely dominated spatial trends of aqueous PCBs in both lakes. Air-water exchange fluxes of $\Sigma_{7} \mathrm{PCBs}$ ranged from $-2,420( \pm 1,870) \mathrm{pg} \mathrm{m}^{-2}$ day $^{-1}$ (deposition) in Sheffield (site E03) to $9,030( \pm 3,070) \mathrm{pg} \mathrm{m}^{-2}$ day $^{-1}$ (volatilization) in Niagara (site On05). Net volatilization of PCBs was the primary trend across most sites and periods. Almost half of variation in air-water exchange fluxes was attributed to the difference in aqueous concentrations of PCBs. Uncertainty analysis in fugacity ratios and mass fluxes in air-water exchange of PCBs indicated that PCBs have reached or approached equilibrium only at the eastern Lake Erie and along the Canadian shore of Lake Ontario sites, where air-water exchange fluxes dominated atmospheric concentrations. 


\section{INTRODUCTION}

The manufacture and import of polychlorinated biphenyls (PCBs) was banned in Canada and the United States in 1977 and 1979,1,2 respectively. In Canada, PCB use was illegal in any electrical products manufactured after 1980, but electrical equipment manufactured prior to 1980 were permitted for continued use. $^{3}$ As persistent organic pollutants, however, PCBs are still being detected in environmental compartments such as water, ${ }^{4}$ air, ${ }^{5}$ sediment, ${ }^{6,7}$ and biota. ${ }^{8,9}$ Due to the concern for the environmental and health effects of PCBs, ${ }^{10}$ they have been frequently monitored and detected in the Great Lakes ecosystem, particularly through the International Atmospheric Deposition Network (IADN). ${ }^{11,12}$

Atmospheric deposition (dry deposition, wet deposition and air-water diffusive fluxes) is a significant source of POPs to large inland lakes, and its importance for PCBs has already been demonstrated in the Great Lakes. ${ }^{13}$ Results from IADN have illustrated the role of atmospheric deposition (gas and particulate $)^{14,15}$ and volatilization ${ }^{16}$ in the atmospheric pathway of PCBs at few designated locations. To improve the knowledge on environmental fate of PCBs in the Great Lakes, more atmospheric and aqueous sampling sites are useful. Although atmospheric PCBs have been extensively investigated in the Great Lakes, ${ }^{17}$ limited information is available about the spatial trend of gaseous and freely-dissolved PCBs. There is a scarcity of recently published data, although a recent survey reported dissolved concentrations for the Great Lakes. ${ }^{4,18}$ This prompted us to deploy passive samplers at more locations across the lakes, to investigate environmental fate of PCBs in air-water exchange processes, and to determine whether the Great Lakes have become an important secondary source of PCBs to the atmosphere. Alternatively, primary emissions continue to deposit 
PCBs into the Lakes, either via atmospheric deposition, or from direct discharges from rivers, wastewater treatment plants and potentially historically contaminated sites. ${ }^{19-22}$ By working on Lakes Erie and Ontario, we also aimed to better understand whether the lake characteristics affected concentrations and trends of PCBs.

Lakes Erie and Ontario constitute the "lower" Great Lakes having the smallest surface area, mean depth and water residence times. Lake Erie has a mean depth of $19 \mathrm{~m}$ and a water residence time of 2.6 years, while Lake Ontario has a mean depth of $86 \mathrm{~m}$ and a water residence time of 6 years. ${ }^{23}$ Lake Erie mainly receives water from Lake Huron via the Detroit River and outflows to Lake Ontario through the Niagara River. Major urban areas include Detroit, Toledo, Cleveland and Buffalo around Lake Erie, and Hamilton, Toronto, Rochester and Kingston around Lake Ontario. It is expensive to conduct active sampling at such a large scale, restricting the assessment of spatial variation of atmospheric and aqueous PCBs and their air-water exchange flux. One way around the restriction is to deploy passive samplers. Published literatures indicated that POPs concentrations from passive atmospheric sampling were in good agreement with those measured with active sampling. ${ }^{24-26}$ In previous work, we performed source apportionment and correlation with urban area of gaseous and freely-dissolved PCBs in the lower Great Lakes covering summer and fall 2011.27 In this study, spatial trends of atmospheric and aqueous PCB concentrations and their air-water exchange fluxes are presented and discussed, with a stronger statistical power based on the two years of data (2011-2012).

To gain more knowledge about the trends and cycling of PCBs in the lower Great Lakes, low density polyethylene (LDPE) passive samplers were deployed 
in the air and water at Lake Ontario and Lake Erie during 2011-2012. Our goals were to a) investigate spatial trend of gaseous and freely-dissolved PCBs in Lakes Erie and Ontario, b) identify their possible sources, c) estimate spatially resolved air-water exchange fluxes, and d) explore the primary factors influencing variability in magnitude and direction of the fluxes in the both lakes.

\section{MATERIALS AND METHODS}

Passive Sampling. Detailed information on sampling sites and temporal coverage is provided in the Supporting Information (Figure S1 and Tables S1-2). A $50.8 \mu$ m-thick LDPE commercial sheeting was cut into strips of $10 \times 40 \mathrm{~cm}$. The strips were cleaned and spiked with performance reference compounds (PRCs) via a method adapted from Booij et al. ${ }^{28}$ The LDPE passive samplers were deployed in the air and water of the Great Lakes region by trained volunteers. Water and air passive samplers were deployed in the same locations whenever possible. Shoreline air samplers were mounted inside two inverted bowls and deployed 1-2 m above the ground or water surface to shelter LDPE samplers from direct radiation and rainfall. Coastal water samplers were fastened to an anchored rope and suspended in water $\sim 1 \mathrm{~m}$ below the surface. Air samplers nearshore (1-2 km from shore) northern Lake Ontario sites were mounted within stainless steel bowl housings $\sim 2 \mathrm{~m}$ above the water surface on buoys. Co-located (within 200 m of air sites) water samplers were suspended below a sub-surface float at $4 \mathrm{~m}$ depth in perforated stainless steel cages anchored at lake-bottom to a stainless steel cable. Mid-lake deployments involved securing the stainless steel wire holding the PEs to rods inside a perforated $(1.5 \mathrm{~cm}$ diameter holes) $10 \mathrm{~cm}$ diameter stainless steel or copper tube (see Figure S2). 
Depending on the location, one to four sampling campaigns of 4-34 weeks were conducted from April of 2011 to October of 2012. Due to logistical constraints, in-lake deployments had fewer sampling deployments than on-land.

Sample Analysis and QA/QC. LDPE samples were processed according to the published method. ${ }^{29,} 30$ Briefly, all LDPE sheets contained PRCs and were spiked with surrogate standards ( ${ }^{13}$ C labeled PCB 8, 28, 52, 118, 138, 180, and 209) and then extracted overnight in pentane for 18 - 24 hours. After extracts were concentrated to $\sim 100 \mu \mathrm{L}$, an injection standard (tribromobiphenyl) was added before analysis. No additional sample clean-up was performed for air samples, while water samples were passed through a silica gel and sodium sulfate column for cleanup. PCBs (29 congeners) were analyzed using Agilent GC 6890N with DB-5 MS fused silica capillary column equipped with a Quattro micro GC tandem MS (Waters), including dichlorobiphenyl (PCB 8 and 11), trichlorobiphenyl (PCB 18 and 28), tetrachlorobiphenyl (PCB 44, 52, 66, 77, and 81), pentachlorobiphenyl (PCB 101, 105, 114, 118, 123, and 126), hexachlorobiphenyl (PCB 128, 138, 153, 156, 157, 167, and 169), heptachlorobiphenyl (PCB 170, 180, 187, and 189), octachlorobiphenyl (PCB 195), nonachlorobiphenyl (PCB 206) and decachlorobiphenyl (PCB 209). PCB concentrations in LDPE samplers were corrected for surrogate standard recoveries and blank-subtracted using the field blank relevant to the sampling location. The PCB concentrations in field blanks were less than $5 \%$ of the measured concentrations in samples, except PCB 8 and 11 (6-23\%). PRC concentrations in field and method blanks from each batch were used to determine initial PRC concentrations in deployed samplers from the same batch. 
Measured concentrations in LDPE were used to calculate ambient concentrations using sampler-matrix partition coefficients corrected to ambient temperatures for each PCB. The calculation is based on an assumption that the uptake rate of target compounds from ambient environment to the LDPE sheet is equal with the loss rate of PRCs from the LDPE sheet to ambient matrix. ${ }^{31}$ Equilibrium percentages of target PCBs were calculated from the quantities of PRCs remaining in each sample. Further analytical details and calculations are provided in the Supporting Information.

Procedural blanks, field blanks, matrix spikes, and replicate samples were performed periodically for quality assurance. Limits of detection were 0.5-13.1 $\mathrm{pg} \mathrm{m}^{-3}$ and $0.2-1.5 \mathrm{pg} \mathrm{L}^{-1}$ in air and water, respectively. Average recoveries of the surrogate standards ranged from $52-108 \%$. Average relative standard deviation percentages of target PCBs and sampling rates ranged from 9.2-36.4\% and $0.5-31.8 \%$. More information on quality assurance and quality control is in the Supporting Information (Tables S6-S7).

\section{Fugacity Ratio between Air and Water and Bivariate Analysis. The} fugacity ratio $\left(f_{\mathrm{a}} / f_{\mathrm{w}}\right)$ was calculated based on PCB concentrations in air $\left(C_{\mathrm{a}}\right)$ and water $\left(C_{\mathrm{w}}\right.$; both in $\left.\mathrm{pg} \mathrm{m}^{-3}\right)$ and (air) temperature-corrected air-water partition coefficient $\left(K_{\mathrm{aw}}\right)$, as shown in Equation 1.

$$
\log \left(f_{\mathrm{a}} / f_{\mathrm{w}}\right)=\log \mathrm{C}_{\mathrm{a}}-\log \mathrm{C}_{\mathrm{w}}-\log \mathrm{K}_{\mathrm{aw}}
$$

The log-transformed fugacity ratios are listed in Table S11 and those of ICES 7 PCBs observed across the Lakes were analyzed via bivariate Pearson correlation (result in Table S14) using SPSS statistical software packages (SPSS 13.0 for windows). 
Quantification of Air-Water Exchange Flux. Air-water mass flux $\left(F_{a / w}\right.$, in $\mathrm{pg}$

$\mathrm{m}^{-2}$ day $^{-1}$ ) is driven by the difference in compound's chemical activity between two matrixes, ${ }^{32}$ see Equation 2.

$$
F_{\mathrm{a} / \mathrm{w}}=v_{\mathrm{a} / \mathrm{w}} \times\left(C_{\mathrm{w}}-C_{\mathrm{a}} / K_{\mathrm{aw}}\right)
$$

where $v_{\mathrm{a} / \mathrm{w}}$ is overall mass transfer velocity (in $\mathrm{m} \mathrm{day}^{-1}$ ) and $K_{\mathrm{aw}}$ is the air temperature-corrected air-water partition coefficient. Details on estimating $v_{\mathrm{a} / \mathrm{w}}$ from wind speed for different temperature are provided in the Supporting Information. The calculated $v_{\mathrm{a} / \mathrm{w}}$ values are presented in Table $\mathrm{S} 10$, and the flux $\left(F_{a / w}\right)$ values are in Table S8.

\section{Error propagation analysis. Uncertainties in air-water fugacity ratios and} calculated mass fluxes were estimated, by taking measured uncertainties in air and water analysis, partitioning coefficients (including temperature and the Henry's law constant, $\left.H_{\mathrm{c}}\right)$ and air-water transfer velocity $\left(v_{\mathrm{a} / \mathrm{w}}\right)$ into account. More details are shown in the Supporting Information. Uncertainties of log-transformed fugacity ratios ranged from 0.53 (CB 153) to 0.60 (CB 128), and the flux uncertainties are listed in Table S9.

\section{RESULTS AND DISCUSSION}

Concentrations of Gaseous and Freely-Dissolved PCBs. In this study, higher molecular weight (octa-, nona- and deca-PCB) congener concentrations in both air and water were typically below their limits of detection, while the other congeners (di-PCBs: 8 and 11; tri-PCBs: 18 and 28; tetra-PCBs: 44, 52, and 66; penta-PCBs: 101, 105, and 118; hexa-PCBs: 138, 153; hepta-PCBs: 180, and 187) 
were detected in most samples. Several, mostly co-planar congeners (PCBs: 77, $81,114,123,126,128,156,157,167,169,170$, and 189), were only detected in a few of the samples (for details, see Table S6).

In active sampling, the 'apparently dissolved' concentration is defined as the fraction passing a fiber filter (e.g. below 0.5 micrometers). ${ }^{4}$ Dissolved concentration is hence an operational classification in active sampling, whereas LDPE passive sampling results reported here represent the freely dissolved concentration (as dissolved organic carbon-bound compounds are not sampled).

In the water, total freely-dissolved concentrations of 29 PCBs were 1.50-83.8 pg L $\mathrm{L}^{-1}$ (average and median values: 30.8 and $23.8 \mathrm{pg} \mathrm{L}^{-1}$ ) in Lake Erie and 6.00-105 $\mathrm{pg} \mathrm{L}^{-1}$ (average and median values: 33.9 and $29.1 \mathrm{pg} \mathrm{L}^{-1}$ ) in Lake Ontario. In the air, total gaseous concentrations of 29 PCBs were $19.0-421 \mathrm{pg} \mathrm{m}^{-3}$ (average and median values: 111 and $80.3 \mathrm{pg} \mathrm{m}^{-3}$ ) across Lake Erie and 7.70-634 pg m $\mathrm{m}^{-3}$ (average and median values: 105 and $80.9 \mathrm{pg} \mathrm{m}^{-3}$ ) across Lake Ontario. The descriptive statistics of the total concentration of freely-dissolved and gaseous 29 PCBs are illustrated in Figure 1.a and b, respectively. The concentrations of PCBs were not significantly different in the both lakes by Student's $t$ test ( $p=0.83)$, in spite of their differences in size, depth and residence time. Similarly, atmospheric PCB concentrations were not significantly different between the two lakes $(p=0.61)$. Anderson et al. reported apparently dissolved phase PCB concentrations ranging from 52-330 $\mathrm{pg} \mathrm{L}^{-1}$ and 110-190 pg $\mathrm{L}^{-1}$ in Lake Erie and Ontario, respectively. ${ }^{33}$ Venier et al. also reported that apparently dissolved phase PCB concentrations (reporting 84 PCBs) were $582 \pm$ $127 \mathrm{pg} \mathrm{L}^{-1}$ and $623 \pm 113 \mathrm{pg} \mathrm{L}^{-1}$ in Lakes of Eric and Ontario, respectively. ${ }^{4}$ All studies agree, though, that Lakes Erie and Ontario display similar PCB 
concentrations in the water.

The seven ICES (International Council for the Exploration of the Sea) PCBs were recommended as monitoring indicators by the European Union Community Bureau of Reference, due to their relatively high concentrations and wide chlorination range (3-7 chlorine atom per molecule), including PCB 28, 52, 101, $118,138,153$, and $180 .{ }^{34}$ Linear regression analyses of total concentrations of ICES 7 PCBs (abbreviated as $\Sigma_{7}$ PCBs) against those of 29 PCBs in air and water were examined, and strongly significant positive correlations between them were observed $(R=0.952$ and 0.889 in air and water, respectively and $p<0.001$, see Figure S3). This confirms that the choice of the 7 congeners as representative for a large suite of PCBs (29 congeners in this study). The 7 congeners are selected as representative PCBs for the following analysis.

\section{Spatial distribution of $\Sigma_{7}$ PCBs.}

Freely-dissolved PCBs in Water. In the water, freely-dissolved concentrations of the 7 PCBs in Lake Erie were comparable with those in Lake Ontario.

Freely-dissolved $\Sigma_{7}$ PCBs were 0.8-39.1 $\mathrm{pg} \mathrm{L}^{-1}$ (average and median values: 13.7 and $12.0 \mathrm{pg} \mathrm{L}^{-1}$ ) in Lake Erie and 1.7-43.7 $\mathrm{pg} \mathrm{L}^{-1}$ (average and median values: 12.9 and $7.5 \mathrm{pg} \mathrm{L}^{-1}$ ) in Lake Ontario. The freely-dissolved PCB levels varied with sampling locations (Figure 2.a). In general, total concentrations along the shore, e.g., $30 \mathrm{pg} \mathrm{L}^{-1}$ in Erie (site E07) and $44 \mathrm{pg} \mathrm{L}^{-1}$ in Niagara (site On05), were relatively higher than those in the open lakes, e.g., $<10 \mathrm{pg} \mathrm{L}^{-1}$ in lakes of Erie (site E08) and Ontario (site On07). Open-lake freely-dissolved PCBs were mainly influenced by atmospheric deposition (see below). The onshore-offshore gradient generally reflected anthropogenic land uses in adjacent urban areas and 
watersheds. Burniston et al. found that PCBs, mercury, PAHs and some

chlorobenzenes exhibited elevated nearshore concentrations in surface water, compared to open lakes and the elevation was indicative of watershed sources. ${ }^{35}$

\section{Freely-dissolved PCBs in Lake Erie. A west-to-east gradient was observed in} Lake Erie (Data in Table S12), and PCBs gradually decreased from $\sim 30 \mathrm{pg} \mathrm{L}^{-1}$ in the western, to $\sim 20 \mathrm{pg} \mathrm{L}^{-1}$ in the central, and to $<10 \mathrm{pg} \mathrm{L}^{-1}$ in the eastern basin. Venier et al. also reported greater PCB concentrations in the western basin than those in the central and eastern basins. ${ }^{4}$ Similar trends were described for freely-dissolved endosulfans, and to a lesser degree for DDTs and chlordanes. ${ }^{29}$ Such west-to-east gradient was also found for PCBs in mink, and could be linked to the Detroit River, a primary source of PCBs to the western basin. ${ }^{36}$ Marvin et al. indicated the influence of the Trenton Channel in the Detroit River as source of dioxin-like PCBs to western Lake Erie via investigating suspended sediment. ${ }^{19}$ Discharge of the Detroit River probably resulted in the high level of freely-dissolved PCBs at site E02 (open lake). ${ }^{19}$ Although nearly 90 percent of total inflow to Lake Erie comes from the Detroit River, ${ }^{37}$ inflow from stream and tributaries draining agricultural lands also delivered PCBs to the western basin. For example, the higher concentrations of PCBs at Toledo (E01) could be attributed to the discharge of Maumee River.

Freely-dissolved PCBs in Lake Ontario. Total concentrations along the US shore, e.g., 20-40 pg L-1 in Niagara (site On05), Rochester (site On09) and Oswego (site On11) sites, were greater than those on the Canadian shore, e.g., $<10 \mathrm{pg} \mathrm{L}^{-1}$ in Mississauga (site On01), Toronto (site On03), Pickering (site 0n06) and Cobourg 
271 (site On08) sites. This US versus Canada comparison might be the result from the

272 Canadian deployments being conducted $1 \mathrm{~km}$ off shore, while the US

273 deployments were truly coastal (in Table S2). A west-to-east gradient was observed along the US shore of Lake Ontario. The $\Sigma_{7} \mathrm{PCB}$ concentrations decreased from $44 \mathrm{pg} \mathrm{L}^{-1}$ in Niagara (site 0n05), to $40 \mathrm{pg} \mathrm{L}^{-1}$ in Rochester (site On09), to $24.2 \mathrm{pg} \mathrm{L}^{-1}$ in Oswego (site On11), and $15 \mathrm{pg} \mathrm{L}^{-1}$ in Cape Vincent (site On12). The main sources of PCBs into Lake Ontario were the Niagara River and its watershed in western New York. ${ }^{38,39}$ The gradient possibly resulted from outflow of the Niagara River and water circulation patterns of Lake Ontario, as shown in Figure 2.a. Helm et al. indicated regional alongshore transport when examining the influence of land based source to lakes and coastal areas. ${ }^{40}$ Along the US coast, the PCB distributions seems to be related to the presence of waste water treatment plants (WWTPs) and urban centers, while along the Canadian shore, there was no obvious correlation to them, as shown in Figure S4. This is likely caused by the Lake Ontario deployments being ca $1 \mathrm{~km}$ offshore and the US deployments being truly coastal. The influence of WWTPs is likely to be very limited on the intra-lake distributions of dissolved PCBs. Helm et al. captured the distribution of wastewater-related contaminants in a nearshore zone of Lake Ontario and found the influence of WWTP was quickly diluted out to 'background' level on the order of less than a kilometer. ${ }^{40}$ Alongshore currents and upwelling seemed to contribute to concentration variation. Historically contaminated resuspended sediment could serve as an additional loading to the lakes, according to an extremely similar spatial pattern of sedimentary PCBs reported by Forsythe and Marvin (in Figure S6). ${ }^{41}$ Compared with Lake Ontario, Lake Erie is shallow and undergoes active resuspension of sediment, which could 
explain the similar west-to-east gradients of aqueous and sedimentary PCBs in Lake Erie.

$$
\text { PCBs in air. Concentrations of gaseous PCBs across Lake Erie were similar to }
$$
those across Lake Ontario. Gaseous $\Sigma_{7} \mathrm{PCBs}$ were 6.7-205 $\mathrm{pg} \mathrm{m}^{-3}$ (average and median values: 41.4 and $30.3 \mathrm{pg} \mathrm{m}^{-3}$ ) across Lake Erie and 5.2-306 $\mathrm{pg} \mathrm{m}^{-3}$ (average and median values: 36.4 and $20.2 \mathrm{pg} \mathrm{m}^{-3}$ ) across Lake Ontario. As shown in Figure 2.b, across Lake Erie, atmospheric concentrations were greatest in the urban area of Cleveland (sites E03 and E05), and lowest at the open lake sites (E04 and E08), while concentrations across Lake Ontario were dominated by elevated concentrations at Cape Vincent (site On12). The distribution of atmospheric PCBs differed significantly from that in the water (Figure 2), indicating that there are different sources contributing to either phase. Air-water exchange gradients indicate net volatilization across most sites and seasons (see below). A possible reason is due to PCB volatilization from (contaminated) terrestrial sites. Greater concentrations of gaseous PAHs were also found in Cleveland, and urban centers were considered as their main source. ${ }^{30}$ As PCBs have been banned in USA and Canada for a long time, their emissions are different from ongoing PAHs emission. It seems reasonable to assume that legacy PCBs in soils along the lakes volatilize back to atmosphere and have become a (secondary) source of gaseous PCBs. Yet Melymuk et al. ${ }^{42}$ also suggested that a major city such as Toronto still has plenty of PCBs in-use in transformers and other uses. Similarly, Khairy et al. ${ }^{29}$ detected a correlation between land use pattern and atmospheric concentrations of several banned OCPs in the region, and suggested that agriculture soils and urban centers were major sources of the 
banned OCPs to the air. In their recent work, ${ }^{27}$ approximately $45 \%$ of PCB sources around Lakes Erie and Ontario resemble 'fresh' Aroclor mixtures, while $27 \%$ resemble 'weathered' Aroclors; the latter could be attributed to volatilization from contaminated soils/sites, while the former could imply their leaching from in-use equipments.

\section{Air-water exchange.}

Fugacity ratios. Air-water exchange gradients of PCBs are described using their fugacity ratios between air and water. Log-transformed fugacity ratios of selected PCBs are cross plotted in Figure 3 and full data are listed in Table S11. Fluxes not significantly different from equilibrium were defined based on error propagation from PCB and temperature measurement and Henry's law constant estimation, detailed in the Supporting Information. In Figure 3, air-water fugacity ratios for most congeners were scattered across the 'evaporation' or 'equilibrium' area, namely $\log \left(f_{\mathrm{a}} / f_{\mathrm{w}}\right)<0$, while a few of ratios were located at the area of 'deposition', that is $\log \left(f_{\mathrm{a}} / f_{\mathrm{w}}\right) \geqslant 0$. This implies that the primary trend of air-water exchange of PCBs is volatilization from water to air across most sites and seasons. Deposition trends of PCBs at sites E03 (Sheffield), E09 (Dunkirk) and On12 (Cape Vincent) were mostly observed during the 2012 autumn, indicating that atmospheric PCBs are still a source to the Lakes at specified sites and periods. It is worth pointing out that the air-water exchange trends at site E09 (Dunkirk) in 2012 depended mainly on the temperature, namely, volatilization during the warming spring, approaching equilibrium in the summer and deposition in the cooling autumn. Furthermore, we observed a strong temperature dependence of atmospheric PCB concentrations at that site 
(data in Table S13). These results imply that site E09 is dominated by secondary sources, which changes in flux direction depending on the temperature. Site E09 was characterized by low concentrations in both air and water, relative to other sites, supporting the absence of dominant primary sources; this could mean that air-water exchange dominated atmospheric concentration of PCBs at this site. In Figure 3, the $\log \left(f_{\mathrm{a}} / f_{\mathrm{w}}\right)$ of PCB 118 is significantly correlated with those of PCB 52, 101, 153 and 180. And such cross-correlation was also widely observed among the 7 PCBs. The Pearson correlation coefficients are listed in Table S14 indicating similar transport trends and proportional fugacity gradients in air-water exchange of different congeners. Furthermore, there is a separation between lighter and heavier PCBs. The correlations are weaker between the lighter and heavier PCB. The correlation coefficients depend on similarity of PCBs.

Air-water exchange fluxes. Air-water exchange mass transfer velocities and fluxes of PCBs ( $\mathrm{pg} \mathrm{m}^{-2}$ day $^{-1}$ ) are listed in Tables S8 and S10, respectively. Mass transfer velocities of PCBs primarily depend on wind speed, temperature, and PCB volatility. The transfer velocity range was $14-98 \mathrm{~cm} \mathrm{day}^{-1}$ in this study and comparable with the PAH transfer velocities $\left(0.2-73 \mathrm{~cm}^{\text {day }}{ }^{-1}\right)$ that McDonough et al. reported. ${ }^{30}$ Net volatilization fluxes were observed across most sites and deployment periods, indicating discharge of rivers and sediment resuspension were more significant sources of freely-dissolved PCBs than atmospheric deposition. Jeremiason et al. indicated that decreases in aqueous PCB concentrations reflected volatilization loss across Lake Superior . ${ }^{16}$ In our work, volatilization fluxes of lighter PCBs were greater than heavier ones (Table S8), 
and the flux patterns primarily depended on volatility of PCB congeners. Total fluxes of the 7 PCBs during deployment periods are presented in Figure 4. The maximum values of volatilization and deposition flux were observed at site 0n05 (Niagara) in the summer $\left(9,030 \pm 3070 \mathrm{pg} \mathrm{m}^{-2}\right.$ day $\left.^{-1}\right)$ and E03 (Sheffield) in the autumn $\left(-2,420 \pm 1870 \mathrm{pg} \mathrm{m}^{-2}\right.$ day $\left.^{-1}\right)$, respectively. Hornbuckle et al. reported much greater air-water exchange fluxes of 77 PCBs from $-18 \mathrm{ng} \mathrm{m}^{-2}$ day-1$^{-1}$ (net deposition) to $60 \mathrm{ng} \mathrm{m}^{-2}$ day-1$^{-1}$ (net volatilization) in Lake Michigan during 1991-1993.43 The significant differences in the fluxes were partly attributed to the difference in wind speeds used by Hornbuckle et al. (5.1 $\mathrm{m} \mathrm{s}^{-1}$ on average) ${ }^{43}$ and this study $\left(4.2 \mathrm{~m} \mathrm{~s}^{-1}\right)$. Higher wind speeds yielded higher overall mass transfer velocities which significantly increased the calculated flux. In addition, Hornbuckle et al. used active sampling, which, particularly in the water phase might lead to increased 'apparent' dissolved concentrations, which would also increase derived water-to-air fluxes.

Strong deposition fluxes were observed only at sites of E03 (Sheffield) and On12 (Cape Vincent) and were driven by the higher concentrations of atmospheric PCBs at the two sites.

In Lake Ontario, higher volatilization fluxes were mostly observed along the US shores (2,220-9,030 $\mathrm{pg} \mathrm{m}^{-2}$ day $^{-1}$ with average value of 4,690 $\mathrm{pg} \mathrm{m}^{-2}$ day $\left.^{-1}\right)$, compared with those in Canada (97-7,390 $\mathrm{pg} \mathrm{m}^{-2}$ day $^{-1}$ with average of 1,390 $\mathrm{pg}$ $\mathrm{m}^{-2}$ day $^{-1}$ ). The surprising difference of fluxes at site 0n08 (Cobourg) was primarily related to differences of wind speeds ( 4.4 and $\left.6.0 \mathrm{~m} \mathrm{~s}^{-1}\right)$ and concentrations of freely-dissolved PCBs (1.9 and $\left.9.6 \mathrm{pg} \mathrm{L}^{-1}\right)$ during two deployment periods. The difference in wind speed translated in a $\sim 2.7$ times difference in mass transfer velocities at the two deployment periods. Air-water 
exchange was approaching equilibrium at the sites with lower concentrations of gaseous and freely-dissolved PCBs, e.g., at the eastern basin of Lake Erie and the Canadian shores in Lake Ontario, implying air-water exchange dominated atmospheric PCB concentrations at these regions. The (near) equilibrium conditions could be related to the deeper water at those sites which weakened the PCB contribution from sediment resuspension.

Pearson correlation analysis was performed between total fluxes of the 7 PCBs and wind speeds, temperatures, atmospheric and aqueous concentrations. Results show that the total fluxes showed a strongly significant negative correlation with atmospheric concentrations, and a strongly significant positive correlation with aqueous concentrations. Hence, stepwise multiple linear regression analysis was conducted to explore primary factors influencing the variability in the magnitude and direction of fluxes in this case. Standardized normal deviations of wind speeds, temperatures, atmospheric and aqueous concentrations and the total fluxes were used as independent and dependent variables, respectively. Variability of the total flux was explained by the four factors $(R$ square $=0.86, p<0.001)$. The major contributor was aqueous concentration, accounting for $47 \%$. Contributions of atmospheric concentration, wind speed and temperature were $23 \%, 20 \%$ and $10 \%$, respectively. Accordingly, spatial variation of air-water exchange fluxes of PCBs primarily depended on aqueous concentrations. Nevertheless, all factors caused changes in direction and the magnitude of air-water exchange to different extent.

\section{IMPLICATIONS}

This study demonstrated that monitoring concentrations of PCBs based on 
passive sampling method is useful to better understand their spatial distribution and behavior, and quantify fluxes between air and water in the lower Great Lakes. Although there may be differences in atmospheric concentrations between passive and active sampling methods, enhanced passive sampling deployments are a logical choice for establishing spatial pattern of atmospheric PCBs. The passive sampling method can be considered as one of complementary methods of active sampling already occurring in the IADN project, enabling a high geospatial resolution and easy storage of duplicate samples as historical record (multiple LDPE sheets in same sampler). In the same vein, utilizing passive samplers for measuring freely-dissolved concentrations will help screen on-going emissions of PCBs to the Great Lakes. Spatial distribution patterns of freely-dissolved PCBs were attributed to river discharge, water circulation pattern and sediment resuspension. Both Lakes display fairly similar PCB concentrations, based on the results presented here, and supported by previous studies, air-water exchange fluxes were either near equilibrium or favored net volatilization. In light of these results, the similarity in freely-dissolved PCB concentrations in both lakes could be fortuitous, driven by contaminated sites and river discharges, rather than resulting from atmospheric deposition. Meanwhile, more sampling sites are needed along Canada shores in Lake Erie and in open lakes to improve knowledge on occurrence, source and transport of semi-volatile organic compounds in the lower Great Lakes.

\section{ASSOCIATED CONTENT}

Supporting Information 
Detailed information on sampler deployment, PCB properties can be found along with calculated sampling rates and overall mass transfer velocities, atmospheric and aqueous concentrations. This material is available free of charge via the Internet at Http://pubs.acs.org.

\section{AUTHOR INFORMATION}

\section{Corresponding Author.}

*E-mail: lohmann@gso.uri.edu

\section{Notes}

The authors declare no competing financial interest.

\section{ACKNOWLEDGEMENTS}

We acknowledge funding from EPA's Great Lakes Restoration Initiative Award GLAS No. 00E00597-0 (Project Officer Todd Nettesheim), the Fundamental Research Funds for the Central Universities of China and the China Scholarship Council supporting passive sampler research in the Great Lakes. We thank Dave Adelman (URI) and our cast of volunteers for passive sampler deployments around Lakes Erie and Ontario and the field staff of the Emergencies, Operational Analytical Laboratories, and Research Support group (Environment Canada Burlington) for open-lake deployments, and the Ontario Ministry of the Environment for near-shore deployments along Lake Ontario.

\section{REFERENCES}

1. Canada, E. Polychlorinated Biphenyls (PCBs). http://www.ec.gc.ca/bpc-pcb/ (Aug 25, 2015).

2. Agency, U. E. P. Basic Information of Polychlorinated Biphenyls (PCBs). 
http://www.epa.gov/wastes/hazard/tsd/pcbs/about.htm (Aug 25, 2015).

3. Diamond, M. L.; Melymuk, L.; Csiszar, S. A.; Robson, M., Estimation of PCB Stocks, Emissions, and Urban Fate: Will our Policies Reduce Concentrations and Exposure? Environ Sci Technol 2010, 44, (8), 2777-2783.

4. Venier, M.; Dove, A.; Romanak, K.; Backus, S.; Hites, R., Flame Retardants and Legacy Chemicals in Great Lakes' Water. Environ Sci Technol 2014, 48, (16), 9563-9572.

5. Csiszar, S. A.; Diamond, M. L.; Daggupaty, S. M., The Magnitude and Spatial Range of Current-Use Urban PCB and PBDE Emissions Estimated Using a Coupled Multimedia and Air Transport Model. Environ Sci Technol 2014, 48, (2), 1075-1083.

6. Marvin, C. H.; Tomy, G. T.; Alaee, M.; MacInnis, G., Distribution of hexabromocyclododecane in Detroit River suspended sediments. Chemosphere 2006, 64, (2), 268-275.

7. Xu, Y. J.; Chen, L.; Huang, Y.; Qiu, J. Z.; Liu, Y., The dose-effect relevance between the Proportional Mixed Soil with Sewage Sludge Compost and Growth Response of the Horticultural Plant. 2009 3rd International Conference on Bioinformatics and Biomedical Engineering, Vols 1-11 2009, 6298-6302.

8. Salamova, A.; Pagano, J. J.; Holsen, T. M.; Hites, R. A., Post-1990 Temporal Trends of PCBs and Organochlorine Pesticides in the Atmosphere and in Fish from Lakes Erie, Michigan, and Superior. Environ Sci Technol 2013, 47, (16), 9109-9114.

9. Rasmussen, P. W.; Schrank, C.; Williams, M. C. W., Trends of PCB concentrations in Lake Michigan coho and chinook salmon, 1975-2010. Journal of Great Lakes Research 2014, 40, (3), 748-754.

10. Ward, M. P.; Jablonski, C.; Semel, B.; Soucek, D., The biological pathway and effect of PCBs on common terns in Lake Michigan. Ecotoxicology 2010, 19, (8), 1513-1522.

11. Buehler, S. S.; Hites, R. A., The Great Lakes' integrated atmospheric deposition network. Environ Sci Technol 2002, 36, (17), 354a-359a.

12. Hillery, B. R.; Simcik, M. F.; Basu, I.; Hoff, R. M.; Strachan, W. M.; Burniston, D.; Chan, C.; Brice, K. A.; Sweet, C. W.; Hites, R. A., Atmospheric deposition of toxic pollutants to the Great Lakes as measured by the Integrated Atmospheric Deposition Network. Environ Sci Technol 1998, 32, (15), 2216-2221.

13. Jiménez, J. C.; Dachs, J.; Eisenreich, S. J., Chapter 8-Atmospheric Deposition of POPs: Implications for the Chemical Pollution of Aquatic Environments. Comprehensive Analytical Chemistry 2015, 67, 295-322.

14. Eisenreich, S. J.; Looney, B. B.; Thornton, J. D., Airborne organic contaminants in the Great Lakes ecosystem. Environ Sci Technol 1981, 15, (1), 30-38.

15. Strachan, W. M.; Eisenreich, S. J., Mass balance accounting of chemicals in the Great Lakes. Long range transport of pesticides: Lewis Publishers, Chelsea, Michigan 1990, 291-301.

16. Jeremiason, J. D.; Hornbuckle, K. C.; Eisenreich, S. J., Pcbs in Lake-Superior, 1978-1992 Decreases in Water Concentrations Reflect Loss by Volatilization. Environ Sci Technol 1994, 28, (5), 903-914.

17. Sun, P.; llora; Basu; Blanchard, P.; Brice, K. A.; Hites, R. A., Temporal and spatial trends of atmospheric polychlorinated biphenyl concentrations near the Great Lakes. Environ Sci Technol 2007, 41, (4), 1131-1136.

18. Buehler, S. S.; Basu, I.; Hites, R. A., Causes of variability in pesticide and PCB concentrations in air near the Great Lakes. Environ Sci Technol 2004, 38, (2), 414-422. 
19. Marvin, C.; Alaee, M.; Painter, S.; Charlton, M.; Kauss, P.; Kolic, T.; MacPherson, K.; Takeuchi, D.; Reiner, E., Persistent organic pollutants in Detroit River suspended sediments: polychlorinated dibenzo-p-dioxins and dibenzofurans, dioxin-like polychlorinated biphenyls and polychlorinated naphthalenes. Chemosphere 2002, 49, (2), 111-120.

20. Marvin, C.; Alaee, M.; Painter, S.; Charlton, M.; Kolic, T.; MacPherson, K.; Reiner, E., Polychlorinated biphenyls (PCBS) and other persistent organic pollutants associated with Detroit River suspended sediments. Evaluating ecosystem results of $P C B$ control measures within the Detroit River-western Lake Erie basin. United Earth Fund 2003, 63-65.

21. Samara, F.; Tsai, C. W.; Aga, D. S., Determination of potential sources of PCBs and PBDEs in sediments of the Niagara River. Environ Pollut 2006, 139, (3), 489-497.

22. Blanchard, P.; Audette, C. V.; Hulting, M. L.; Basu, I.; Brice, K.; Backus, S.; Dryfhout-Clark, H.; Froude, F.; Hites, R.; Nielson, M.; Wu, R., Atmospheric Deposition of Toxic Substances to the Great Lakes: IADN Results through 2005. US EPA and Environment Canada, US EPA 905-R-08-001.: 2008; p 226.

23. Wikipedia Great Lakes. http://en.wikipedia.org/wiki/Great_Lakes (Aug 25, 2015).

24. Peverly, A. A.; Ma, Y. N.; Venier, M.; Rodenburg, Z.; Spak, S. N.; Hornbuckle, K. C.; Hites, R. A., Variations of Flame Retardant, Polycyclic Aromatic Hydrocarbon, and Pesticide Concentrations in Chicago's Atmosphere Measured using Passive Sampling. Environ Sci Technol 2015, 49, (9), 5371-5379.

25. Khairy, M. A.; Lohmann, R., Field calibration of low density polyethylene passive samplers for gaseous POPs. Environ Sci-Proc Imp 2014, 16, (3), 414-421.

26. Melymuk, L.; Robson, M.; Helm, P. A.; Diamond, M. L., Evaluation of passive air sampler calibrations: Selection of sampling rates and implications for the measurement of persistent organic pollutants in air. Atmos Environ 2011, 45, (10), 1867-1875.

27. Khairy, M.; Muir, D.; Teixeira, C.; Lohmann, R., Spatial Distribution, Air-Water Fugacity Ratios and Source Apportionment of Polychlorinated Biphenyls in the Lower Great Lakes Basin. Environ Sci Technol 2015, in press.

28. Booij, K.; Smedes, F.; van Weerlee, E. M., Spiking of performance reference compounds in low density polyethylene and silicone passive water samplers. Chemosphere 2002, 46, (8), 1157-1161. 29. Khairy, M.; Muir, D.; Teixeira, C.; Lohmann, R., Spatial Trends, Sources, and Air-Water Exchange of Organochlorine Pesticides in the Great Lakes Basin Using Low Density Polyethylene Passive Samplers. Environ Sci Technol 2014, 48, (16), 9315-9324.

30. McDonough, C. A.; Khairy, M. A.; Muir, D. C. G.; Lohmann, R., Significance of Population Centers As Sources of Gaseous and Dissolved PAHs in the Lower Great Lakes. Environ Sci Technol 2014, 48, (14), 7789-7797.

31. Booij, K.; Smedes, F., An Improved Method for Estimating in Situ Sampling Rates of Nonpolar Passive Samplers. Environ Sci Technol 2010, 44, (17), 6789-6794.

32. Schwarzenbach, R. P.; Gschwend, P. M.; Imboden, D. M., Environmental Organic Chemistry (2nd edition). Wiley Interscience: USA, 2002.

33. Anderson, D. J.; Bloem, T. B.; Blankenbaker, R. K.; Stanko, T. A., Concentrations of polychlorinated biphenyls in the water column of the Laurentian Great Lakes: Spring 1993. Journal of Great Lakes Research 1999, 25, (1), 160-170.

34. Webster, L.; Roose, P.; Bersuder, P.; Kotterman, M.; Haarich, M.; Vorkamp, K., Determination of Polychlorinated Biphenyls (PCBs) in sediment and biota. In ICES Techniques in Marine Environmental 
Sciences, International Council for the Exploration of the Sea: 2013; Vol. 53, pp 1-23.

35. Burniston, D.; Klawunn, P.; Backus, S.; Hill, B.; Dove, A.; Waltho, J.; Richardson, V.; Struger, J.; Bradley, L.; McGoldrick, D., Spatial distributions and temporal trends in pollutants in the Great Lakes 1968-2008. Water Qual Res J Can 2011, 46, (4), 269-289.

36. Martin, P. A.; Mcdaniel, T. V.; Hunter, B., Temporal and spatial trends in chlorinated hydrocarbon concentrations of mink in Canadian Lakes Erie and St. Clair. Environ Monit Assess 2006, 113, (1-3), 245-263.

37. Vaughn, R.; Harlow, G., Report on pollution of Detroit River, Michigan waters of Lake Erie and their tributaries. US Department of Health, Education and Welfare. Public Health Service, Division of Water Supply and Pollution Control 1965.

38. Marvin, C. H.; Charlton, M. N.; Stern, G. A.; Braekevelt, E.; Reiner, E. J.; Painter, S., Spatial and temporal trends in sediment contamination in Lake Ontario. Journal of Great Lakes Research 2003, 29, (2), 317-331.

39. Howdeshell, M. J.; Hites, R. A., Is the Hyde Park Dump, near the Niagara River, still affecting the sediment of Lake Ontario? Environ Sci Technol 1996, 30, (3), 969-974.

40. Helm, P. A.; Howell, E. T.; Li, H.; Metcalfe, T. L.; Chomicki, K. M.; Metcalfe, C. D., Influence of nearshore dynamics on the distribution of organic wastewater-associated chemicals in Lake Ontario determined using passive samplers. Journal of Great Lakes Research 2012, 38, 105-115.

41. Forsythe, K. W.; Marvin, C. H., Analyzing the spatial distribution of sediment contamination in the lower Great Lakes. Water Qual Res J Can 2005, 40, (4), 389-401.

42. Melymuk, L.; Robson, M.; Csiszar, S. A.; Helm, P. A.; Kaltenecker, G.; Backus, S.; Bradley, L.; Gilbert, B.; Blanchard, P.; Jantunen, L., From the city to the lake: Loadings of PCBs, PBDEs, PAHs and PCMs from Toronto to Lake Ontario. Environ Sci Technol 2014, 48, (7), 3732-3741.

43. Hornbuckle, K. C.; Sweet, C. W.; Pearson, R. F.; Swackhamer, D. L.; Eisenreich, S. J., Assessing Annual Water-Air Fluxes of Polychlorinated-Biphenyls in Lake-Michigan. Environ Sci Technol 1995, 29, (4), 869-877.

44. Beletsky, D.; Saylor, J. H.; Schwab, D. J., Mean circulation in the Great Lakes. Journal of Great Lakes Research 1999, 25, (1), 78-93.

45. Minar, N. Wind History. http://windhistory.com/map.html\#7.00/41.828/-78.724 (Aug 25, 2015). 
589 Figure 1. Comparison of aqueous (a) and atmospheric (b) total concentrations of 590 29 PCBs in Lakes Erie and Ontario.

Figure 2. Average aqueous (a) and atmospheric (b) concentrations of $\Sigma_{7} \mathrm{PCBs}$ in lakes of Erie and Ontario. Water circulation as described by Beletsky et al., ${ }^{44}$ and prevailing wind direction provided by Wind History. ${ }^{45}$ water $\left(f_{\mathrm{w}}\right)$ in different sampling sites.

Figure 4. Air-water exchange flux of $\Sigma_{7} \mathrm{PCBs}$. 


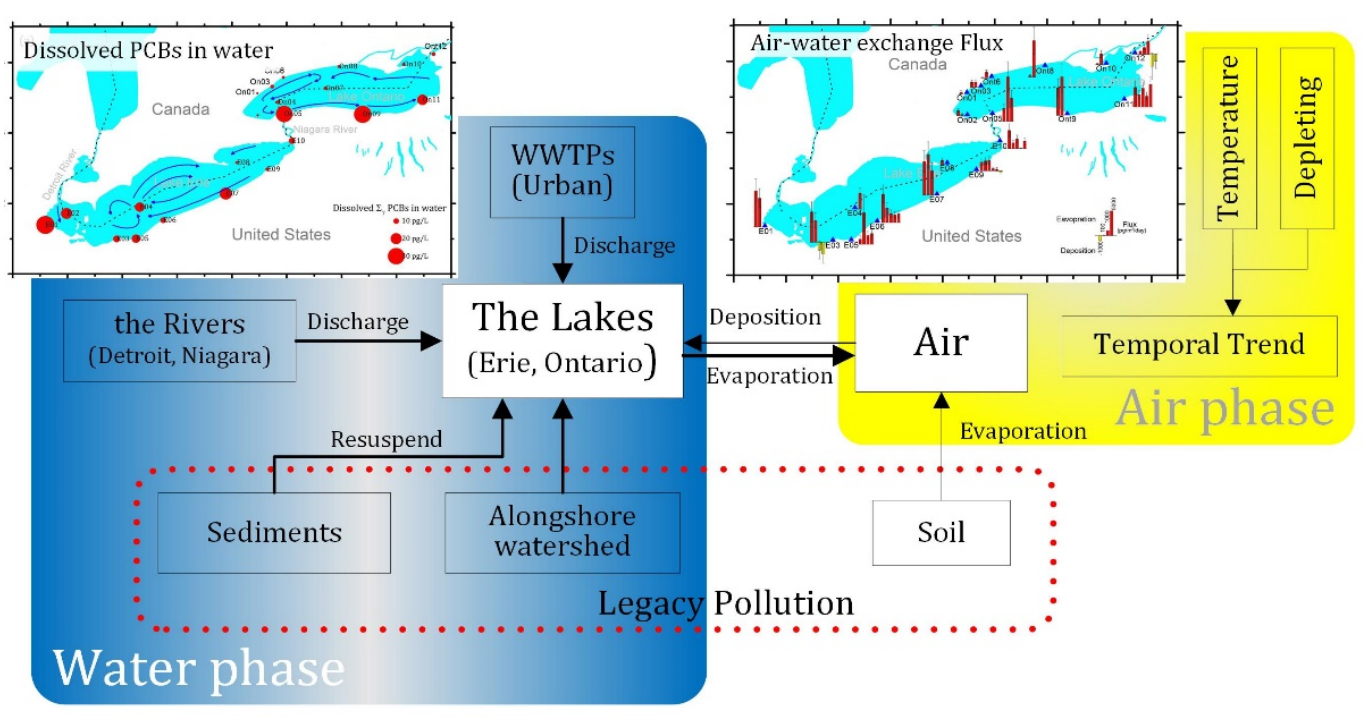

597

598

ABSTRACT ART

599 

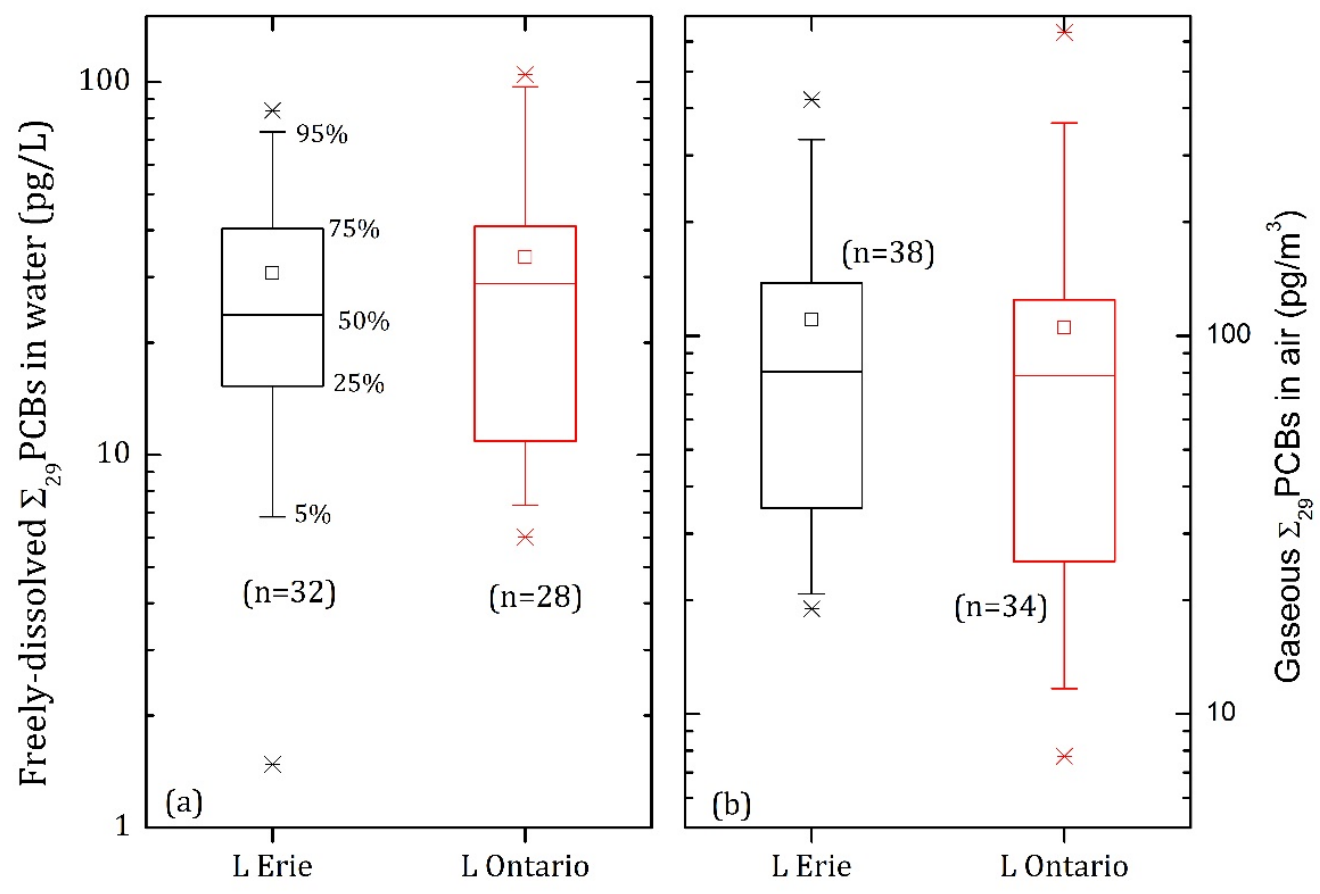

600

601

602

603

Figure 1. Comparison of aqueous (a) and atmospheric (b) total concentrations of 29 PCBs in Lakes Erie and Ontario.

604 

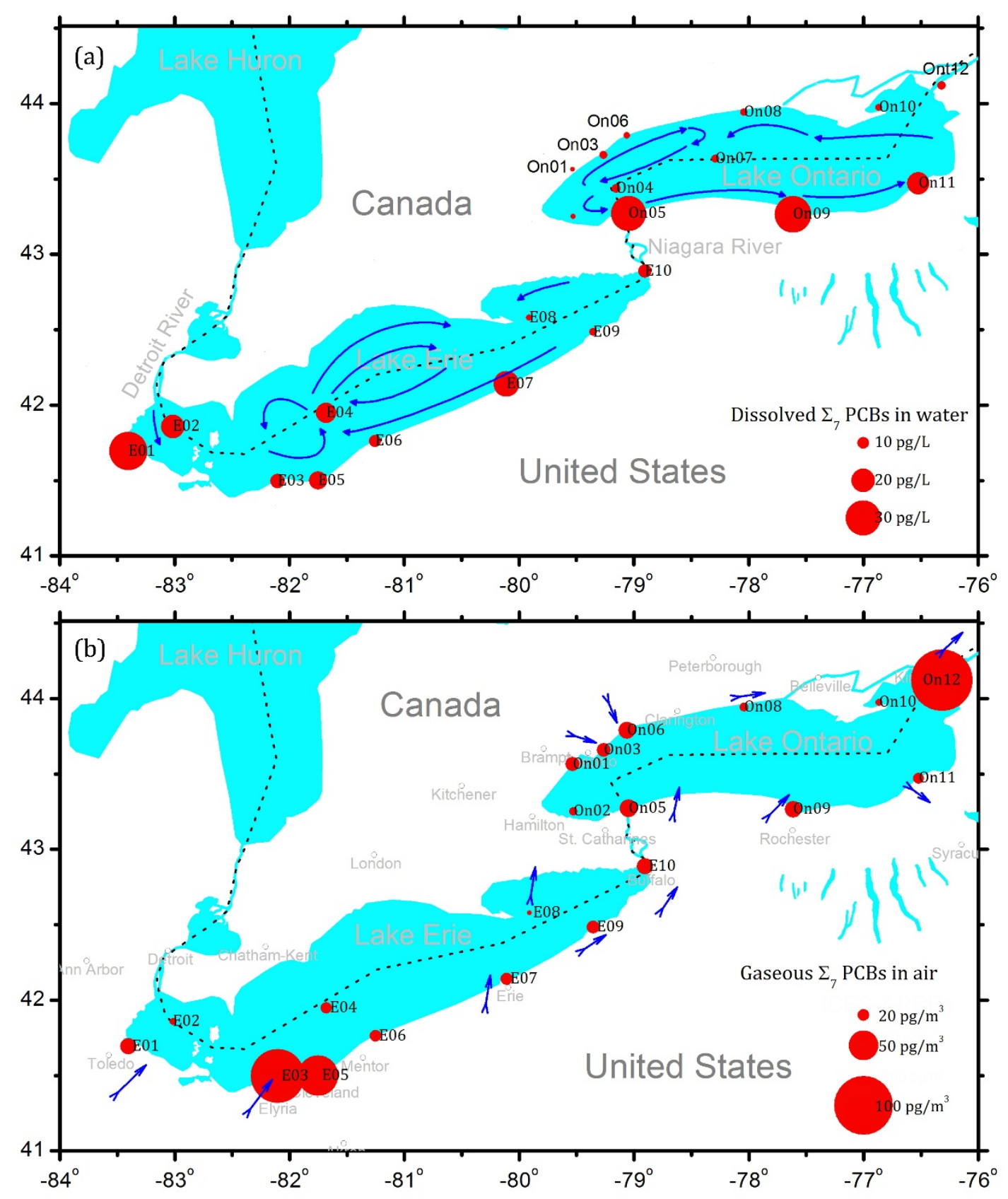

Figure 2. Average aqueous (a) and atmospheric (b) concentrations of $\sum_{7} \mathrm{PCBs}$ in Lake Erie and Ontario. Water circulation as described by Beletsky et al., ${ }^{44}$ and prevailing wind direction provided by Wind History. ${ }^{45}$ 

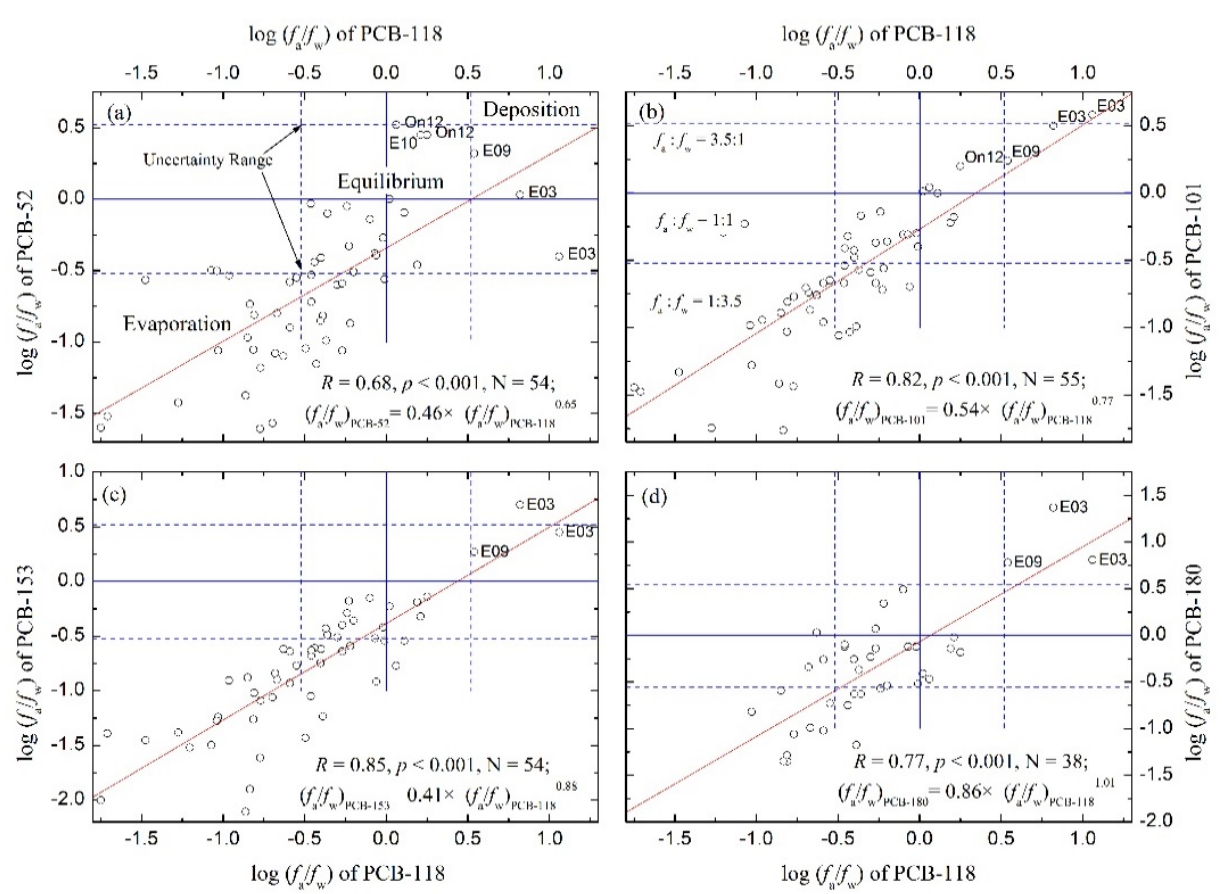

612

Figure 3. Cross plots of log-transformed fugacity ratios between air $\left(f_{\mathrm{a}}\right)$ and water $\left(f_{\mathrm{w}}\right)$ in different sampling sites. The blue line represents equilibrium, and the dashed blue lines represent the uncertainty range around the equilibrium.

617 


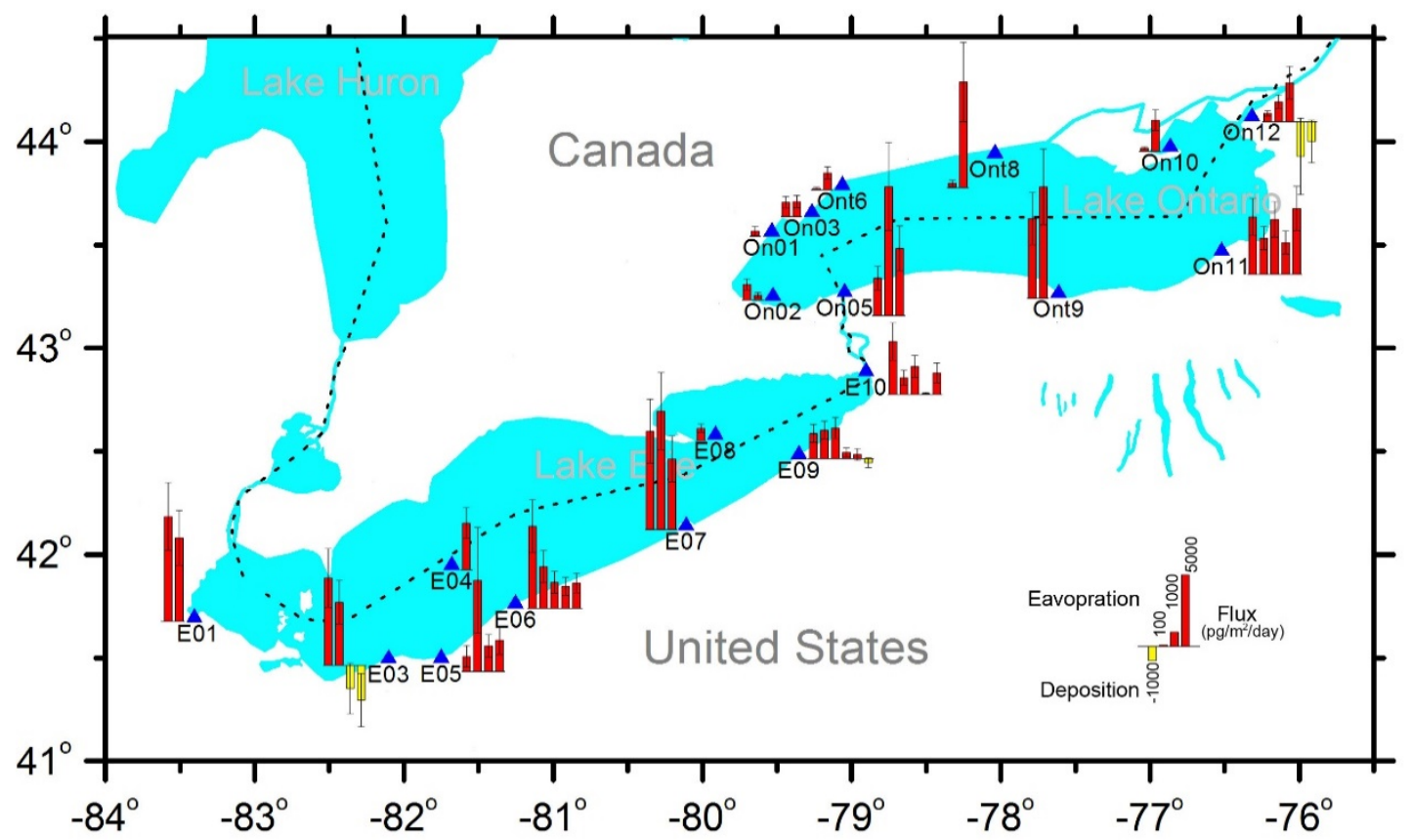

621 Figure 4. Air-water exchange flux of $\Sigma_{7} \mathrm{PCBs}$.

622 